\title{
Pengaruh Kinesio Taping terhadap Intensitas Low Back Pain pada Kehamilan Trimester Tiga
}

\author{
Mira Dyani Dewi, ${ }^{1}$ Anita Deborah Anwar, ${ }^{1}$ R. M. Sonny Sasotya, ${ }^{1}$ Rachmat Zulkarnain, ${ }^{2}$ \\ Sofie Rifayani Krisnadi, ${ }^{1}$ Benny Hasan Purwara, ${ }^{1}$ Hadi Susiarno ${ }^{1}$ \\ Departemen Obstetri dan Ginekologi Fakultas Kedokteran Universitas Padjadjaran \\ Rumah Sakit Dr. Hasan Sadikin Bandung \\ ${ }^{2}$ Departemen Ilmu Kedokteran Fisik dan Rehabilitasi Fakultas Kedokteran Universitas \\ Padjadjaran/RSUP Dr. Hasan Sadikin \\ Korespondensi: Mira Dyani Dewi, Email: miradyani@gmail.com
}

\begin{abstract}
Abstrak
Tujuan: Penelitian ini adalah untuk menganalisis karakteristik pasien Low Back Pain (LBP), menganalisis perbedaan penurunan intensitas LBP dan keterbatasan aktivitas pada kelompok yang diberikan kinesio taping dan parasetamol dengan kelompok yang diberikan parasetamol

Metode : Penelitian ini adalah penelitian kuantitatif dengan desain eksperimental dengan melakukan uji klinis metode Pretest-Posttest Control Group Design yang dilakukan dengan menilai sebelum dan setelah perlakukan pada kelompok kontrol dan intervensi.

Hasil : Penelitian didapatkan perbedaan penurunan intensitas nyeri Numeric Rating Scale (NRS) yang bermakna pada kelompok kontrol dan intervensi sebesar 33,3\% dan $60 \%$ dengan nilai $\mathrm{p}<0,001$ dan perbedaan penurunan keterbatasan aktivitas Rolland Morris Disability Questionaire (RMDQ) yang bermakna pada kelompok kontrol dan intervensi sebesar 25,0\% dan 55,6\% dengan nilai $\mathrm{p}<0,001$. Kesimpulan : Terdapat perbedaan penurunan intensitas LBP dan keterbatasan aktivitas yang bermakna pada kelompok yang mendapatkan intervensi kinesio taping dibandingkan dengan kelompok kontrol yang tidak mendapatkan kinesio taping
\end{abstract}

Kata kunci : kinesio taping, low back pain dalam kehamilan, keterbatasan aktivitas, numerical rating scale (NRS), Rolland Morris Disability Questionnaire (RMDQ)

\section{Effect Of Kinesio Taping to the Intensity of Low Back Pain in Third Trimester Pregnancy}

\begin{abstract}
Objective : This research aims to analyze the characteristics patient who suffer LBP and to analyze the differences in LBP intensity and activity limitations in the groups that given kinesio taping and paracetamol with groups that given paracetamol only.

Method: This research is quantitative research by conducting clinical test of Pretest-Posttest Control Group Design method which is done by assessing before and after treatment in control and intervention group.

Result : The results showed significant difference in pain intensity Numeric Rating Scale (NRS) in control and intervention group by 33.3\% and 60\% with $p<0.001$ and significant difference in activity limitation Rolland Morris Disability Questionaire (RMDQ) in control and intervention group by $25.0 \%$ and $55.6 \%$ with $p$ value $<0.001$.

Conclusion : This research conclusion there was a significant differences in decreasing LBP intensity activity limitations in the group receiving the kinesio taping intervention compared with the control group who did not receive kinesio taping
\end{abstract}

Key words : kinesio taping, low back pain in pregnancy, activity limitation, numerical rating scale (NRS), Rolland Morris Disability Questionnaire (RMDQ) 


\section{Pendahuluan}

Low back pain (LBP) merupakan masalah kesehatan yang sering terjadi selama kehamilan dan memiliki dampak terhadap individu, keluarga maupun lingkungan. LBP dalam kehamilan sudah menjadi masalah global yang terjadi baik di negara maju maupun di negara berkembang. Prevalensi LBP dilaporkan bervariasi dari 50\% di Inggris dan Skandinavia serta $70 \%$ di Australia. Prevalensi yang tinggi juga telah dilaporkan dari benua Eropa, Amerika, Australia, dan China. Nyeri punggung pada kehamilan dipengaruhi oleh ras dan etnik. ${ }^{1}$

Berdasarkan laporan profil datakesehatan Indonesia tahun 2015, terdapat 5.298.285 orang ibu dan sebanyak $20 \%$ di antaranya mengalami LBP. Sebanyak 50\% wanita hamil mengalami LBP, dan 30\% diantaranya mengalami keterbatasan aktivitas. ${ }^{1,2}$ Dari penelitian lain didapatkan sebanyak $16 \%$ wanita hamil mengeluh LBP pada kehamilan 12 minggu, $67 \%$ pada kehamilan 24 minggu dan sebanyak 93\% pada usia kehamilan 36 minggu. Dari penelitian yang ada, LBP yang dirasakaan ibu hamil sebagian besar adalah di daerah sakral, diikuti lumbosakral, lumbal dan torakal, hanya sedikit ibu hamil yang mengeluh nyeri bagian servikal. ${ }^{3}$

LBP yang disebabkan kehamilan memiliki pengaruh yang besar pada suatu individu, khususnya mereka yang mengeluh nyeri dengan intensitas yang berat jika dibandingkan dengan ibu hamil yang tidak menderita LBP sama sekali. ${ }^{4}$ Pada studi prospektif, sekitar 30-35\% wanita dengan nyeri LBP sulit melakukan aktivitas seharihari, berjalan, duduk dalam waktu yang lama, membawa tas atau melakukan aktivitas yang mengharuskan mencondongkan badan ke depan. ${ }^{5}$ Hal ini menunjukkan bahwa LBP yang dialami wanita hamil berakibat pembatasan aktivitas yang disebabkan karena kehamilan itu sendiri. ${ }^{4}$

Beberapa penjelasan dan patofisiologi yang menyebabkan LBP telah dijelaskan, termasuk adanya peningkatan beban punggung yang disebabkan peningkatan berat badan selama kehamilan, penambahan berat janin, perubahan hormonal selama kehamilan, yang menyebabkan ketidakstabilan vertebra dan sendi sakroiliaka dan menyebabkan rasa nyeri. ${ }^{1,6}$ Seiring pertumbuhan janin, pertambahan berat badan ibu akan berubah, hal ini menyebabkan berubahnya pusat gravitasi tubuh, peregangan otot dan juga menyebabkan lemahnya otot-otot abdomen. Keadaan ini menyebabkan berubahnya postur tubuh salah satunya dengan berubahnya lengkungan kurvatura tulang belakang (menjadi semakin lordosis), yang berdampak pada terjadinya LBP. . $^{1,4,5,6}$

Ada berbagai cara dilakukan untuk mengatasi keluhan LBP ini, diantaranya yaitu : latihan dan modalitas, stabilization belt, stimulasi saraf, terapi farmakologis, akupuntur, massage, relaksasi, senam yoga dan kinesio taping. Kinesio taping digunakan oleh para klinisi sebagai metode untuk menyuport proses rehabilitasi dan memodulasi beberapa proses fisiologis. ${ }^{7}$ Taping pada sendi meningkatkan stabilitas sendi sehingga dapat menurunkan spasme otot, dan nyeri. Mekanisme kerja kinesio taping diantaranya yaitu: menyupport injuri pada otot dan sendi, memperbaiki fungsi dan posisi fascia, meningkatkan stabilitas segmen sendi, memperbaiki aliran pembuluh darah dan aliran lymph dengan mengangkat lapisan kulit, deaktivasi rasa nyeri dengan menurunkan stimulus nociceptor. ${ }^{8}$ Dari penelitian didapatkan bahwa terdapat penurunan intensitas nyeri yang signifikan pada wanita kehamilan trimester tiga dengan kinesio taping dibandingkan dengan pemberian obat antinyeri (parasetamol), ${ }^{2,9}$

Parasetamol atau asetaminofen merupakan suatu analgetik sistemik non opioid, yang memiliki efikasi dan keamanan yang baik di setiap usia kehamilan. Banyak penelitian yang telah membuktikan keamanan 
parasetamol selama kehamilan, dosis yang dianjurkan untuk pemberian parasetamol yaitu 3x500 mg. ${ }^{710}$ Intensitas nyeri secara deskriptif dapat diukur menggunakan 4 cara, yaitu verbal descriptor scale (VDS), numeric rating scale (NRS), visual analogue score (VAS), dan pengukuran skala nyeri menurut Bourbanis. Dari keempat cara tersebut, metode penialian skala intensitas nyeri yang paling objektif dan paling sering digunakan untuk menilai instensitas nyeri sebelum dan setelah intevensi terapeutik adalah numeric rating scale (NRS). ${ }^{7,8,9}$

\section{Metode}

Tipe penelitian ini adalah penelitian kuantitatif dengan desain eksperimental dengan melakukan uji klinis metode PretestPosttest Control Group Design.

Rancangan Pretest-Posttest Control Group Design dilakukan dengan menilai sebelum dan setelah perlakukan pada kelompok kontrol dan intervensi. Penelitian seperti ini disebut sebagai penelitian kuasi eksperimen (eksperimen semu), dimana menggunakan seluruh objek dalam kelompok belajar (intact group) untuk diberi perlakuan (treatment), bukan menggunakan subjek yang diambil secara acak. Subyek penelitian diberi perlakuan terapi kinesio taping. Teknik kinesio taping dapat menurunkan intensitas nyeri LBP pada kehamilan trimester tiga. Variabel terikat dibandingkan melalui pengukuran sebelum dan setelah perlakuan. Hasil penelitian selanjutnya akan dianalisis secara statistik.

Teknik sampling yang digunakan dalam penelitian ini adalah nonprobability sampling dengan metode consecutive sampling. Nonprobability sampling adalah teknik pengambilan sampel yang tidak memberi peluang atau kesempatan sama bagi setiap unsur atau anggota kelompok untuk dipilih menjadi sampel. Consecutive sampling adalah prosedur sampling untuk mendapatkan orang-orang atau unit dan teknik penentuan pengambilan sampel dengan urutan kedatangan pasien yang sesuai berdasarkan kriteria inklusi dan kriteria eksklusi.

Dari data yang terkumpul, akan diolah dan dianalisis secara deskriptif dan analitik. Untuk deskriptif dengan menyajikan ukuran statistik, jumlah dan persentase untuk data kategorik, sedangkan untuk data numerik dengan menghitung rata-rata, simpangan deviasi, median dan rentang. Untuk perhitungan analitik akan menggunakan uji statistik. Uji statistik yang digunakan adalah:

1. Uji $t$ tidak berpasangan untuk membandingkan perbedaan rata-rata dari variable yang diteliti, jika data tidak berdistribusi normal digunakan uji MannWhitney

2. Uji t berpasangan untuk membandingkan perbedaan skala nyeri sebelum dan sesudah intervensi, atau uji Wilcoxon jika data tidak berdistribusi normal

3. Untuk menganalisis korelasi dari berbagai karakteristik (usia, paritas, dan pertambahan berat badan selama kehamilan) dengan penurunan NRS digunakan analisis korelasi RankSpearman.

Kemaknaan hasil uji ditentukan berdasarkan nilai $\mathrm{p}<0,05$.

\section{Hasil}

Penelitian tentang tentang pengaruh pemberian kinesio taping dan parasetamol terhadap intensitas nyeri dan skor keterbatasan aktivitas pada kehamilan trimester tiga telah dilakukan masing-masing terhadap 19 orang. Untuk pengukuran intensitas nyeri digunakan numeric ranting scale (NRS) dan untuk keterbatasan aktivitas digunakan skor Rolland Morris Disability Questionaire (RMDQ). Pengukuran dilakukan sebelum dan sesudah pemberian perlakuan. Hasil 
penelitian selengkapnya disajikan berikut ini.

Dari tabel 1 tampak data karakteristik pada kedua kelompok yang meliputi usia, pekerjaan, paritas dan pertambahan berat badan selama kehamilan, nilai awal intensitas nyeri dan keterbatasan aktivitas tidak menunjukkan ada perbedaan yang bermakna ( $p>0,05)$. Dengan homogenitas karakteristik pada kedua kelompok ini maka layak dapat diperbandingkan.

Grafik 1 menyajikan perbedaan skor intensitas nyeri sebelum dan sesudah perlakuan diberikan. Tampak hasil uji statistik dengan uji Mann-Whitney intensitas nyeri sebelum perlakuan tidak menunjukkan ada perbedaan yang bermakna $(\mathrm{p}>0,05)$, sedangkan sesudah perlakuan dan persentase penurunannya pada kedua kelompok

Tabel 1 Perbandingan Karakteristik Subjek Penelitian pada kelompok Intervensi dan Kelompok Kontrol

\begin{tabular}{|c|c|c|c|}
\hline \multirow[b]{2}{*}{ Variabel } & \multicolumn{2}{|c|}{ Kelompok } & \multirow[b]{2}{*}{ Nilai $p$} \\
\hline & $\begin{array}{c}\text { Intervensi } \\
(n=19)\end{array}$ & $\begin{array}{c}\text { Kontrol } \\
(n=19)\end{array}$ & \\
\hline Usia & & & 0,340 \\
\hline$<35$ tahun & $18(94,7 \%)$ & $15(78,9 \%)$ & \\
\hline$>=35$ tahun & $1(5,3 \%)$ & $4(21,1 \%)$ & \\
\hline Pekerjaan & & & - \\
\hline Bekerja & $0(0,0 \%)$ & $0(0,0 \%)$ & \\
\hline Tidak Bekerja & $19(100,0 \%)$ & $19(100,0 \%)$ & \\
\hline Paritas & & & 0,305 \\
\hline Primipara & $5(26,3 \%)$ & $8(42,1 \%)$ & \\
\hline Multipara & $14(73,7 \%)$ & $11(57,9 \%)$ & \\
\hline $\begin{array}{l}\text { Pertambahan berat badan } \\
\text { selama masa kehamilan }\end{array}$ & & & 0,433 \\
\hline Rerata (SD) & $10,02(4,38)$ & $10,97(2,88)$ & \\
\hline Rentang & $3,30-19,40$ & $6,00-16,50$ & \\
\hline Skala Nyeri (NRS) & & & 0,729 \\
\hline Median & 5 & 5 & \\
\hline Rentang & $5-8$ & $5-6$ & \\
\hline Keterbatasan Aktivitas & & & \\
\hline (RMDQ) & & & 0,525 \\
\hline Median & 4,5 & 4,5 & \\
\hline Rentang & $2-10$ & $3-9,5$ & \\
\hline
\end{tabular}

Keterangan : Nilai p untuk usia diuji dengan uji eksak Fisher; paritas dengan uji Chi-kuadrat; pertambahan BB dengan uji t. Nilai $p>0,05$ artinya tidak menunjukkan ada perbedaan yang bermakna. 


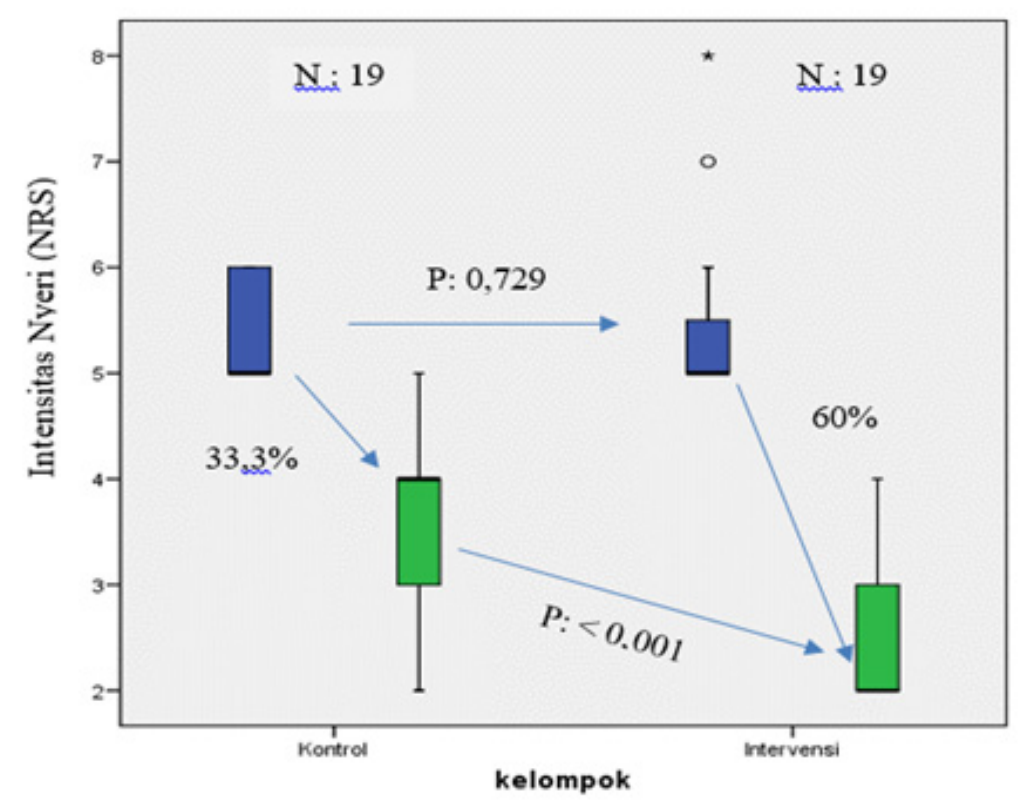

Median nyeri pre Median nyeri post

Gambar 1 Perbandingan Penurunan Intensitas Nyeri (NRS) pada Kelompok Intervensi dan Kelompok Kontrol

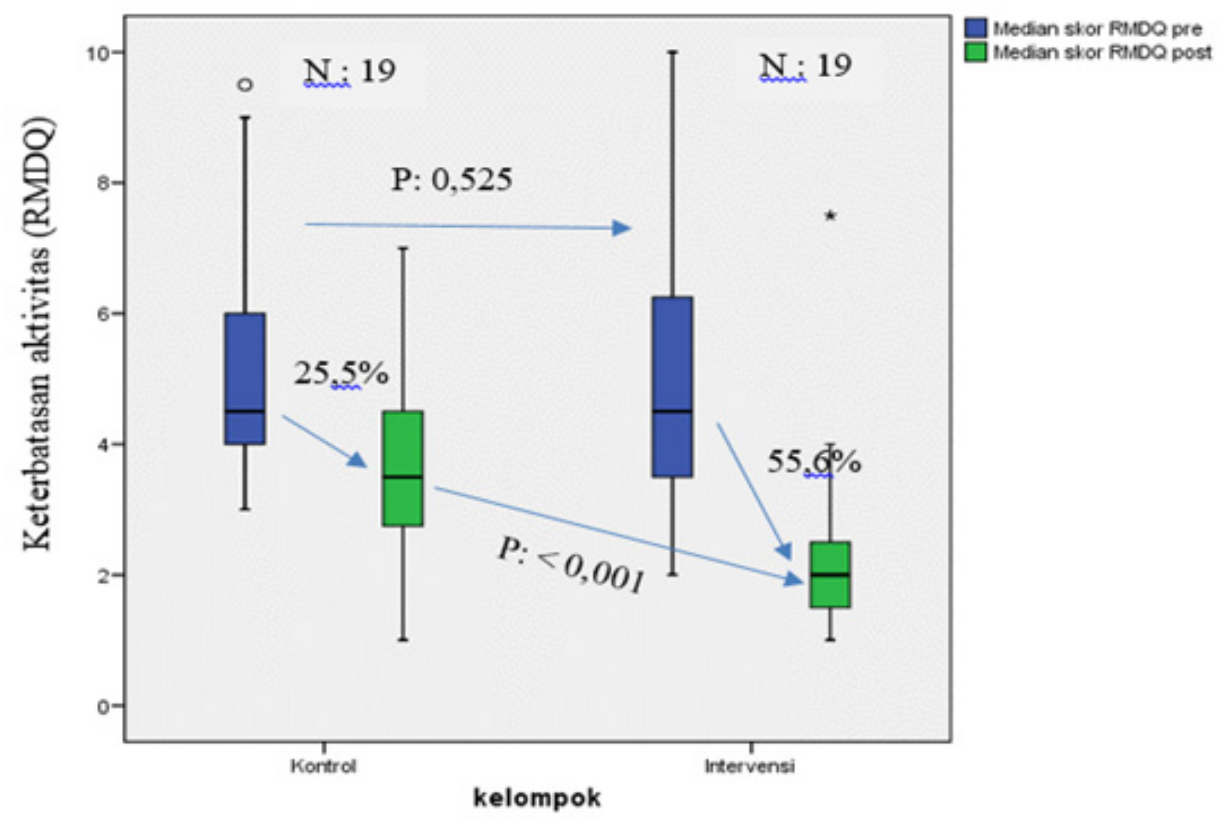

\section{Gambar 2 Perbandingan Penurunan Keterbatasan Aktivitas (RMDQ) pada Kelompok Intervensi dan Kelompok Kontrol}

perlakuan menunjukkan ada perbedaan yang bermakna $(\mathrm{p}<0,05)$. Pada kedua kelompok penelitian terjadi penurunan skor nyeri, untuk kelompok intervensi dari median skor nyeri 5 menjadi 2, dan untuk kelompok kontrol dari skor 5 menjadi 4 dan perbedaan penurunan ini pada kedua kelompok perlakuan menunjukkan ada perbedaan yang bermakna 
berdasarkan uji Wilcoxon. Berdasarkan persentase penurunan skor nyeri pada kelompok perlakuan mediannya adalah $60 \%$ dan pada kelompok kontrol sebesar 33,3\%.

Grafik 2 menyajikan perbandingan penurunan keterbatasan aktivitas (RMDQ) dari kedua kelompok perlakuan pada sebelum dan sesudah perlakuan diberikan. Pada data awal sebelum perlakuan diberikan median skor RMDQ tidak menunjukkan ada perbedaan yang bermakna $(p>), 05)$, sedangkan setelah perlakuan diberikan menunjukkan ada perbedaan yang bermakna $(\mathrm{p}<0,05)$, dengan median skor pada kelompok perlakuan adalah 2 dan pada kelompok kontrol 3,5. Perbandingan antara pengukuran data awal dan data akhir pada kedua kelompok perlakuan secara statistik dengan uji Wilcoxon menunjukkan ada perbedaan yang bermakna $(p<0,05)$. Jika dihitung persentase penurunan keterbatasan aktivitas pada kelompok perlakuan turun sebesar 55,6 \% dan pada kelompok kontrol turun sebesar 25,0\%; perbedaan persentase penurunan keterbatasan aktivitas (RMDQ) pada kedua kelompok perlakuan ini secara statistik dengan uji Mann-Whitney adalah bermakna $(\mathrm{p}<0,05)$.

\section{Pembahasan}

Karakteristik subjek penelitian yang dibandingkan pada penelitian ini adalah usia, paritas, penambahan berat badan selama kehamilan, pekerjaan, dan intensitas nyeri awal. Karena faktor-faktor tersebut dapat menjadi faktor perancu terhadap hasil penelitian ini. Untuk dapat membandingkan kelompok intervensi dan kelompok kontrol, maka karakteristik subjek harus homogen.

Berdasarkan hasil penelitian didapatkan nilai $\mathrm{p}$ untuk usia pada kedua kelompok kontrol adalah 0,340 , nilai $\mathrm{p}$ untuk pekerjaan pada kedua kelompok adalah 1.000, nilai $\mathrm{p}$ untuk paritas pada kedua kelompok adalah 0,305 , nilai $\mathrm{p}$ untuk pertambahan berat badan selama masa kehamilan pada kedua kelompok adalah 0,433 . Nilai $\mathrm{p}$ dari semua subjek penelitian $>0,05(\mathrm{p}>0,05)$ yang berarti tidak signifikan atau tidak bermakna secara statistik, dengan demikian dapat dijelaskan bahwa tidak terdapat perbedaan persentase yang signifikan secara statistic antara variable usia, pekerjaan, paritas, pertambahan berat badan selama kehamilan pada kelompok intervensi dan kelompok kontrol, hal ini menunjukkan kedua kelompok sama atau homogen artinya layak untuk dibandingkan dan dilakukan hipotesis lebih lanjut. Pada penelitian yang dilakukan oleh Mota MJ dkk, didapatkan bahwa usia rata-rata wanita yang mengalami LBP saat hamil yaitu rentang usia 25-35 tahun, dengan Body Mass Index (BMI) sebelum hamil 24,2 \pm 4,6 kg dan BMI setelah hamil 29,2 $\pm 5,0 \mathrm{~kg}$, kemudian 55,2\% adalah primipara dan $44,8 \%$ multipara. ${ }^{10}$ Penelitian lain yang dilakukan oleh Wang $\mathrm{dkk}$, didapatkan bahwa usia rata-rata wanita yang mengalami LBP pada kehamilan yaitu $31,5 \pm 4,8$ tahun. ${ }^{1,3}$

Perbandingan intensitas nyeri yang diukur menggunakan numerical rating scale (NRS) pada kedua kelompok, sebelum dan sesudah intervensi menunjukkan hasil yang signifikan dengan nilai $\mathrm{p}<0,001$ pada kedua kelompok, namun demikian jika dilihat dari persentase penurunan intensitas nyeri pada kelompok intervensi dan kelompok kontrol, terlihat bahwa kelompok intervensi memiliki persentase penurunan intensitas nyeri yang lebih besar yaitu sebanyak $60 \%$ dibandingkan pada kelompok kontrol yang hanya sebesar $33,3 \%$, perbedaan penurunan intensitas nyeri pada kedua kelompok sangat signifikan dengan nilai $\mathrm{p}<0,001$.

Pada penelitian yang dilakukan oleh Kaplan dkk, terdapat 2 kelompok penelitian yaitu kelompok kontrol yang terdiri dari $\mathrm{ibu}$ hamil trimester tiga yang mengalami LBP diberikan parasetamol, sedangkan kelompok intervensi yang terdiri dari ibu hamil trimester tiga yang mengalami LBP 
diberikan parasetamol dengan penambahan kinesio taping, didapatkan hasil bahwa kedua kelompok mengalami penurunan yang signifikan dengan $p<0,01$, namun grup intervensi memiliki penurunan intensitas nyeri yang sangat signifikan dengan nilai $\mathrm{p}<0,001$.

Pada penelitian yang dilakukan oleh Sabbour dkk, terdapat 2 kelompok penelitian yaitu kelompok kontrol yang terdiri dari ibu hamil trimester tiga yang mengalami LPB, diberikan latihan pelvic titling selama kehamilan, dan kelompok intervensi yang terdiri dari ibu hamil trimester tiga yang mengalami LBP, diberikan latihan pelvic titling dengan penambahan kinesio taping, didapatkan hasil bahwa kedua kelompok mengalami penurunan yang signifikan dengan nilai $p<0,01$ namun persentase penurunan antara kedua grup, jauh lebih signifikan pada kelompok intervensi yang diberikan tambahan kinesio taping yaitu sebesar $69,8577 \%$ pada kelompok intervensi dan $18,7744 \%$ pada kelompok kontrol. ${ }^{11}$ Pada penelitian yang dilakukan oleh Kuciel dkk, yang dilakukan pada 24 wanita hamil dengan low back pain rentang usia kehamilan 18-34 minggu, skala nyeri diukur menggunakan visual analogue scale sebelum dan sesudah dilakukan intervensi kinesio taping selama 5 hari, memiliki hasil bahwa terdapat penurunan intensitas nyeri yang signifikan setelah diberikan kinesio taping di hari ke-3 dan hari ke-5 setelah aplikasi kinesio taping dengan nilai $\mathrm{p}: 0,0123$ pada hari ke-3 dan nilai p: 0,0334 pada hari ke-5. ${ }^{11}$

Pada penelitian yang dilakukan oleh Kalinowski dkk, yang dilakukan pada 2 kelompok wanita hamil dengan LBP. Kelompok A menggunakan placebo (tape menyerupai kinesio taping), kelompok B menggunakan kinesio taping. Skala nyeri diukur pada sebelum aplikasi, sesaat setelah aplikasi, hari ke-2 aplikasi dan hari ke-7 aplikasi kinesio taping menggunakan visual analogue scale (VAS) dengan nilai $\mathrm{p}<0,0001$, dibandingkan pada kelompok placebo dengan nilai $p: 0,8087 . .^{12}$

Penelitian ini sejalan dengan yang telah dilakukan oleh Kaplan dkk, dan Sabbour dkk, Kuciel dkk dan Kalinowski dkk, yaitu terdapat penurunan intensitas nyeri yang signifikan pada kelompok yang diberikan intervensi kinesio taping dibandingkan dengan kelompok kontrol (latihan pelvic titling dan pemberian parasetamol saja).

Low back pain (LBP) pada kehamilan trimester tiga disebabkan oleh beberapa faktor, diantaranya peregangan mekanik karena kehamilan, kelemahan ligament pelvis, kompresi pembuluh darah, kompresi neuronal. Salah satu teori yang paling banyak menyebabkan LBP adalah dengan adanya pembesaran uterus kehamilan, menyebabkan lumbar lordosis (perubahan centre of gravity) sebagai kompensasinya, dan hal ini menimbulkan peregangan yang berlebihan di daerah punggung sehingga menyebabkan LBP. Kelemahan ligamen yang disebabkan produksi hormon relaxin dan estrogen selama kehamilan berhubungan dengan remodelling serat kolagen dan mengaktifkan system collagenolytic pun dapat menjadi salah satu penyebab LBP, sehingga pada kehamilan, LBP dapat disebabkan karena kombinasi dari beban mekanik, hormonal, sirkulasi dan faktor psikososial. Beberapa dari wanita yang mengalami LBP dengan intensitas yang berat, disertai dengan keterbatasan aktivitas seharihari seperti berjalan, duduk dalam waktu yang lama, atau aktivitas yang mengharuskan membungkuk ke depan, seperti membereskan tempat tidur. $6,15,16$,

Parasetamol sebagai analgetik yang juga dikenal dengan nama asetaminofen yang paling aman digunakan selama kehamilan di berbagai usia kehamilan. Cara kerja parasetamol yaitu dengan menghambat aktivitas cyclooxygenase (COX) di otak sehingga dapat berperan ganda sebagai antipiretik dan analgetik yang dapat mengurangi intensitas LBP. ${ }^{18}$ 
Kinesio taping sebagai modalitas lain dalam menangani LBP pada kehamilan memiliki beberapa fungsi yang dapat mengurangi intensitas LBP dan mengurangi keterbatasan aktivitas akibat LBP, yaitu :

- Menyokong otot dan sendi yang mengalami cedera

- Memperbaiki fungsi dan posisi fascia

- Meningkatkan stabilitas segmen otot

- Mengaktivasi aliran lymph dan pembuluh darah, dan deaktivasi nyeri dengan menurunkan stimuli nociceptor. ${ }^{19}$

Regangan kinesio taping yang digunakan pada kasus ini yaitu $20 \%$ dan $50 \%$, hal ini berkaitan dengan penyebab LBP pada ibu hamil yang disebabkan oleh kelemahan ligament pelvis, kompresi pembuluh darah, kompresi neuronal. Regangan yang berfungsi sebagai space correction guna melancarkan aliran darah, lymph dan reservasi neuronal yaitu regangan tape ringan-sedang 25$50 \%$, sedangkan untuk ligament correction diperlukan regangan yang sedang-berat 50 $75 \%$. $^{7,20,55}$

\section{Daftar Pustaka}

1. Ayanniyi O. Low Back Painin Pregnancy: The Realityandthe Challenge. Ghana Journal of Physiotherapy. 2015;4(1):27-39.

2. Candotti CT, Noll M, Marchetti BV, Rosa BNd, Medeiros MdGS, Vieira A, et al. Prevalence of back pain, functional disability, and spinal postural changes. Fisioterapia em Movimento. 2015;28(4):711-22.

3. Wang S-M, Dezinno P, Maranets I, Berman MR, Caldwell-Andrews AA, Kain $\mathrm{ZN}$. Low back pain during pregnancy: prevalence, risk factors, and outcomes. Obstet Gynecol. 2004;104(1):65-70.

4. Katonis P, Kampouroglou A, Aggelopoulos A, Kakavelakis K, Lykoudis S, Makrigiannakis A, et al. Pregnancy-related low back pain.
Hippokratia. 2011;15(3):205-10.

5. Ayanniyi O, Sanya A, Ogunlade S, OniOrisan M. Prevalence and pattern of back pain among pregnant women attending ante-natal clinics in selected health care facilities. Afr J Biomed Res. 2006;9(3).

6. Yousef AM, Hanfy HM, Elshamy FF, Awad MA. Postural changes during normal pregnancy. 2011.

7. Gutke A, Betten C, Degerskär K, Pousette S, Fagevik Olsén M. Treatments for pregnancy related lumbopelvic pain: a systematic review of physiotherapy modalities. Acta Obstet Gynecol Scand. 2015;94(11):1156-67.

8. Hall H, Cramer H, Sundberg T, Ward L, Adams J, Moore C, et al. The effectiveness of complementary manual therapies for pregnancy-related back and pelvic pain: A systematic review with meta-analysis. Medicine. 2016;95(38).

9. Bharti N, Arora R, Arora L. Effectiveness OfKinesio-TapingOnPainAndFunctional Disability On Non-Specific Low Back Pain-A Randomized Clinical Trial. Int $\mathbf{J}$ of Adv Res. 2015;3(10):1159-63.

10. Mota MJ, Cardoso M, Carvalho A, Marques A, Sá-Couto P, Demain S. Women's experiences of low back pain during pregnancy. Journal of back and musculoskeletal rehabilitation. 2015;28(2):351-7.

11. 11. Kuciel N, Sutkowska E, Cienska A, Markowska D, Wrzosek Z. Impact of Kinesio Taping application on pregnant women suffering from pregnancy-related pelvic girdle pain-preliminary study. Ginekol Pol. 2017;88(11):620-5.

12. 12. Kalinowski P, Krawulska A. Kinesio Taping vs. Placebo in Reducing Pregnancy-Related Low Back Pain: A Cross-Over Study. Med Sci Monit. 2017;23:6114.

13. Katonis $\mathrm{P}$, Kampouroglou A, Aggelopoulos A, Kakavelakis K, Lykoudis S, Makrigiannakis A, et 
al. Pregnancy-related low back pain. Hippokratia. 2011;15(3):205-10.

14. Sabbour A. The effect of Kinesiotaping therapy augmented with pelvic tilting exercises on low back pain in primigravidas during the third trimester. Bull Fac 2011;16(1).

15. Casagrande D, Gugala Z, Clark SM, Lindsey RW. Low Back Pain and Pelvic Girdle Pain in Pregnancy. J Am Acad Orthop Surg. 2015;23(9):539-49.

16. Malhotra S, Khanna S. Safety of analgesics in pregnancy. Int $\mathrm{J}$ Obstet Gynaecol Res. 2016;3(1):208-12.

17. Zhou Y, Ng J, Mok N. Kinesio taping can improve movement kontrol of lumbar spine in people with non-specific chronic low back pain. 2016.

18. Streuling I, Beyerlein A, Rosenfeld E, Hofmann H, Schulz T, Von Kries R. Physical activity and gestational weight gain: a meta analysis of intervention trials. BJOG. 2011;118(3):278-84.

19. Kase K, Kase T. Clinical therapeutic applications of the Kinesio taping method. In: CoLtd K, editor. Tokyo; 2016. 